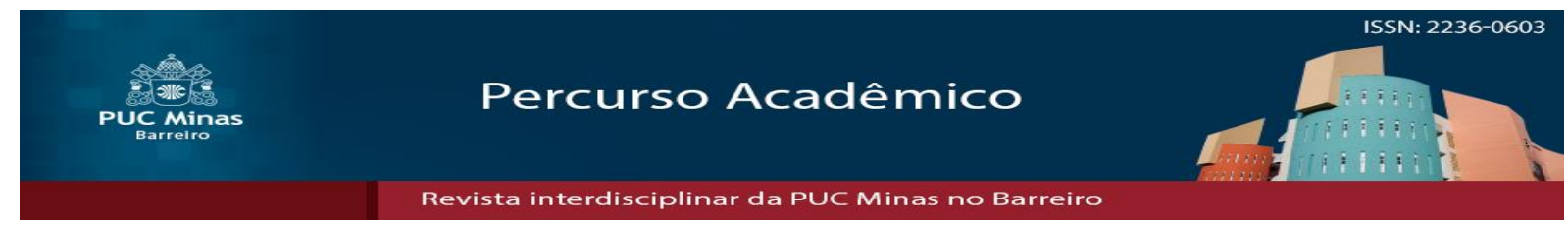

\title{
Perspectivas de aplicação do Gerenciamento de projetos em micro e pequenas empresas: \\ um estudo no setor alimentício da cidade de Betim/MG
}

\section{Perspectives of application of the Project Management in micro and small companies: a study in the food sector of the city of Betim / MG}

Jaqueline Silva Melo ${ }^{1}$

Tatiane Lúcia de Melo

\section{Resumo}

O conjunto de conhecimentos em gerenciamento de projetos pode ser apresentado por uma série de capacitações e competências na área de gestão que são aceitas por projetos de diversas naturezas. Este trabalho buscou investigar a aplicação das práticas do Gerenciamento de Projetos em micro e pequenas empresas da cidade de Betim/MG, do segmento de alimentação, especificamente nos restaurantes da região central da cidade. Seu embasamento teórico buscou dar um suporte conceitual ao tema proposto, bem como contextualizar a realidade das micro e pequenas empresas no Brasil e na cidade alvo deste estudo. Para tal, foi realizada uma pesquisa aplicada, de natureza qualitativa, onde foram utilizados questionários semiestruturados para a coleta de dados. Os resultados da pesquisa demonstraram que o perfil do empreendedor nesse ramo foi predominantemente do sexo masculino, com nível médio de escolaridade e baixo nível de conhecimento e aplicabilidade das práticas de gerenciamento de projetos preconizadas pelo PMI (Project Management Institute). No entanto, a maioria dos

\footnotetext{
Artigo recebido em 30 de Abril de 2019 e aprovado em 15 de Julho de 2019

${ }^{1}$ Mestre em Administração pela PUC Minas. É pós-graduada em Engenharia de Produção e em Gerenciamento de Projetos pela Faculdade Pitágoras. Possui graduação em Fisioterapia, é graduanda em Administração pela Pontifícia Universidade Católica de Minas Gerais (PUC-MG). Atualmente é Supervisora de Logística e Infraestrutura da PUC-MG - Unidade Betim, Coordenadora Adjunta e professora do Curso de Especialização em Gerenciamento de Projetos do IEC - Instituto de Educação Continuada da PUC MG. Brasil. E-mail: jsm@pucminas.br

${ }^{2}$ Especialista em Gestão de Pessoas e de Projetos Sociais pela Universidade Federal de Itajubá e possui MBA em Gestão Estratégica de Pessoas pela Faculdade Pitágoras e é graduada em Psicologia pela Pontifícia Universidade Católica de Minas Gerais (PUC-MG). Possui certificação PMD-Pro 1, que confere reconhecimento internacional em gerência de projetos sociais e de desenvolvimento. Tem experiência na área de Projetos, Gestão de pessoas e Aprendizagem. Atualmente é mestranda do Programa de Pós Graduação em Administração da PUC-MG. Brasil. E-mail: tatyeac@ yahoo.com.br
} 
entrevistados manifestou interesse em conhecer e aplicar estas práticas. A fim de enriquecer as pesquisas na área, sugerimos a realização de outras investigações mais profundas visando a disseminação e incentivo da aplicação das práticas em Gerenciamento de Projetos nesse nicho de mercado.

Palavras-chave: Gerenciamento de Projetos. Empreendedorismo. Gestão.

\section{Abstract}

The set of knowledge in project management can be presented by a series of capacities and competences in the area of management that are accepted by projects of diverse natures. This work aimed to investigate the application of Project Management practices in micro and small companies in the city of Betim / MG, in the food segment, specifically in restaurants in the central region of the city. Its theoretical background sought to give a conceptual support to the proposed theme, as well as to contextualize the reality of micro and small companies in Brazil and in the target city of this study. For this, an applied research was carried out, of a qualitative nature, in which semistructured questionnaires were used to collect data. The results of the research showed that the profile of the entrepreneur in this field was predominantly male, with a mean level of education and a low level of knowledge and applicability of the project management practices recommended by the Project Management Institute (PMI). However, most respondents expressed an interest in knowing and applying these practices. In order to enrich the research in this area, we suggest further research to disseminate and encourage the application of Project Management practices in this market niche.

Key-words: Project Management. Entrepreneurship. Management.

\section{Introdução}

O Gerenciamento de Projetos vem exigindo estudos e pesquisas de várias áreas do conhecimento devido a sua eficácia e grande aplicabilidade na atualidade, seja na área privada, em grandes ou pequenas empresas, na esfera pública e também no chamado terceiro setor, composto por iniciativas da sociedade civil. 
De acordo com uma pesquisa realizada pelo SEBRAE (2013), 56\% das empresas fecham antes de completar três anos de vida. Nesse sentido, considerando as dificuldades inerentes ao processo que vai da concepção à consolidação de micro e pequenas empresas, supõe-se que a prática madura e eficaz dos processos de gerenciamento de projetos não seja realizada de forma plena e com a devida aplicação. Tal situação pode ser ainda agravada se tais empreendedores não possuírem suas formações na área de gestão, onde o aprendizado ocorrerá de forma amadora, com situações de tentativas e erros. Além disso, podem ocorrer situações onde não existem suportes de especialistas para a condução do negócio.

Dessa forma, localizamos um cenário que apresenta dados concretos que sinalizam as dificuldades encontradas por empreendedores na construção e manutenção de suas empresas. Como mencionamos acima, esses problemas podem derivar tanto de erros e equívocos no processo de construção do plano de negócio até o gerenciamento dos projetos executados por essas microempresas, sendo isto muitas vezes relacionado ao despreparo destes empreendedores.

Neste trabalho, realizamos um estudo qualitativo, do tipo aplicado, sobre o gerenciamento de projetos em microempresas, a fim de investigar as principais características e dificuldades deste campo específico. Para tal, o estudo terá sua estrutura dividida em 5 seções, sendo elas, a introdução, na qual se inserem os objetivos, justificativa e a metodologia da pesquisa; em seguida, o embasamento teórico buscará trazer a definição de projetos e do seu gerenciamento, buscando elucidar sua importância de forma teórica. Além disso, faz-se necessário contextualizar, neste capítulo, a importância das micro e pequenas empresas, assim como apresentar seu contexto no município de Betim; resultados e discussão dos resultados são os dois tópicos seguintes e, por fim, as considerações finais.

\subsection{Objetivos}

\subsubsection{Objetivo geral}

Investigar qual a aplicação das práticas do Gerenciamento de Projetos nas microempresas do setor alimentício da cidade de Betim/MG. 


\subsubsection{Objetivos específicos}

- Abordar os conceitos básicos do gerenciamento de projetos;

- Apresentar as definições conceituais e uma breve contextualização das micro e pequenas empresas no Brasil;

- Investigar o nível de conhecimento em Gerenciamento de Projetos por parte dos micro e pequenos empresários do setor alimentício do município de Betim;

- Identificar quais os processos do gerenciamento de projetos são utilizados nas micro e pequenas empresas, no ramo de restaurantes, do município de Betim;

\subsection{Justificativa}

O contexto atual das organizações apresenta uma série de desafios que as levam à busca constante por melhorias nos processos dos produtos e serviços, com o objetivo de se manterem em um mercado altamente competitivo e exigente.

Segundo Carvalho (2011), a sobrevivência de uma empresa, nos dias de hoje, requer dos seus executivos ações rápidas, consequentes e coerentes. Não é possível desperdiçar nenhum tipo de oportunidade, ainda mais, é preciso criá-las. Para manter uma empresa no mercado, é preciso de muito conhecimento, dedicação, esforço, acompanhamento e práticas gerenciais que a direcionem com eficiência e eficácia no sentido de alcançar resultados desejados. Segundo uma pesquisa do SEBRAE (2017), $56 \%$ das empresas fecham antes de completar três anos de vida.

O gerenciamento de projetos tem se mostrado, nos últimos anos, como uma alternativa eficaz para os executivos alcançarem seus resultados de forma sustentável, visto que o mesmo possui uma metodologia consagrada nas grandes empresas. Para Carvalho (2011), de forma geral, todas as empresas vivem de projetos, mesmo aquelas cujo produto final não seja gerado por um projeto. Sabe-se que as ditas atividades inteligentes de projetos são responsáveis por 25\% do PIB mundial, o que representa algo em torno de US\$ 10 trilhões, segundo informações do Project Management Institute (PMI). (CARVALHO, 2011). 
A partir do exposto, a presente pesquisa apresenta a seguinte indagação: como se dá a aplicação do gerenciamento de projetos em micro e pequenas empresas, especificamente no ramo alimentício da cidade de Betim/MG?

\subsection{Metodologia}

O presente trabalho apresenta uma pesquisa aplicada, onde, segundo Parra Filho (1998), existe um interesse de resultados imediatos e, além disso, em sua maioria, visam à utilização prática. Tal pesquisa apresentou uma abordagem qualitativa, pois, segundo Oliveira (2001), tem como objetivo situações complexas e estritamente particulares. $\mathrm{O}$ mesmo autor afirma que as pesquisas que utilizam este tipo de abordagem possuem a facilidade de poder alcançar diversos aspectos, como descrever a complexidade de uma determinada hipótese ou problema, compreender e classificar processos dinâmicos experimentados por grupos sociais, interpretar as particularidades dos comportamentos ou atitudes dos indivíduos, entre outras possibilidades.

Foi realizada uma pesquisa de campo na qual, para a coleta de dados, utilizou-se um questionário semiestruturado. De acordo com Oliveira (2001), trata-se de um instrumento que serve de apoio ao pesquisador para a coleta de dados e precisa, dentre outras coisas, ser a espinha dorsal de qualquer levantamento, reunir todas as informações necessárias, ter uma linguagem adequada, possuir imaginação, experiência e conhecimento.

Os questionários eram compostos de perguntas que abordavam desde informações a respeito do estabelecimento, como número de funcionários, até a formação dos entrevistados, nível de conhecimento acerca das ferramentas do gerenciamento de projetos e aplicação destas na empresa. Foram distribuídos, de forma intencional e por conveniência dos autores, um total de 18 questionários em restaurantes da região central do município de Betim, dos quais 14 proprietários se colocaram à disposição para responder à pesquisa.

\section{$2 O$ gerenciamento de projetos na atualidade}

Nas últimas décadas, as empresas têm passado por um intenso processo de transformação visando a criação de respostas eficazes para os seus problemas. Para isto, o investimento na adoção de técnicas e ferramentas da gestão de projetos tem sido 
fundamental e tem se tornado também uma preocupação crescente nas empresas. (CARVALHO; RABECHINI, 2011).

A sobrevivência de uma empresa requer de seus gerentes ações rápidas e coerentes. Para manter um bom funcionamento de uma organização, é preciso muito conhecimento, esforço e escolha de um conjunto de práticas gerenciais que a conduzam a resultados relevantes. Nesse contexto, trabalhar com o gerenciamento de projetos é dispor de competências individuais e da organização, seguindo estratégias bem definidas, estabelecimento de processos e efetivação de mudanças. (CARVALHO; RABECHINI,

2011).

Maximiano (1997) afirma que os projetos variam muito quanto a sua finalidade, complexidade e volume de recursos empregados. Contudo, destaca o autor, apesar das variações os princípios de administração utilizados devem ser sempre os mesmos, sendo:

1) A administração de projetos é uma técnica (ou conjunto de técnicas) que se aplica a determinadas situações; 2) A aplicação de técnicas da administração de projetos depende tanto da natureza intrínseca da situação quanto de escolha consciente; 3) A tarefa básica da administração de projetos é assegurar a orientação do esforço para um resultado. Controlar custos e prazos é condição básica para realizar o resultado. (MAXIMIANO, 1997, p. 40).

Para compreendermos um pouco mais sobre o gerenciamento de projetos, é preciso que abordemos alguns conceitos básicos da área, como, por exemplo, o ciclo de vida de um projeto e as áreas que compõem o gerenciamento de projetos. Abordar esses conceitos e processos nos permitirá compreender os assuntos que serão discutidos na análise dos dados obtidos em nossa pesquisa de campo com os gerentes dos restaurantes do município de Betim.

\subsection{O gerenciamento de projetos: conceitos}

Segundo Vargas (2016), projeto é um empreendimento não repetitivo, caracterizado por uma sequência clara e lógica de eventos, com início, meio e fim, que se destina a atingir um objetivo claro e definido, executado por pessoas dentro dos requisitos determinados de tempo, custo, recursos destinados e qualidade.

De acordo com o Project Management Institute - PMI (2017), projeto é um esforço temporário canalizado para criar um produto, serviço ou resultado único. E se faz necessário gerenciar estes projetos para que os requisitos que foram elencados na 
sua data de início sejam verdadeiramente alcançados. Ao aplicar e integrar os conhecimentos, habilidades, ferramentas e técnicas às atividades inerentes ao projeto, as organizações têm maior chance de executar seus projetos de forma eficaz e eficiente.

O resultado ou o produto advindo do planejamento de um projeto é um plano, que segundo o autor, "consubstancia as decisões, tomadas em um determinado momento e em um dado nível, e que visa à consecução de objetivos finais a serem alcançados em determinado período". (VALERIANO, 1998, p. 15). Nesse sentido, é importante mencionar a importância do futuro ser levado em consideração, sendo elencadas probabilidades e variáveis contingenciais, a fim de que o plano possa ter maiores chances de ser realizado.

Devido a amplitude que um plano pode apresentar, sua administração pode ser facilitada através da estruturação de programas, que são "subdivisões que permitem agrupar as decisões e as ações por áreas afins ou objetivos setoriais". (VALERIANO, 1998, p. 17). Não obstante, também podemos nomear como programa um conjunto de projetos e atividades gerenciados de forma coordenada cujos benefícios, como esclarece o PMI (2017), seriam difíceis de serem obtidos se gerenciados isoladamente.

\footnotetext{
"O programa (geralmente com o nome do sistema produto/ serviços que administra) dispõe de uma gerência, incumbida do planejamento, da supervisão e do acompanhamento de todas as ações (todos os projetos e atividades que o compõe) durante todo o ciclo de vida deste sistema, desde sua concepção até o encerramento de seu uso como um bem ou serviço." (VALERIANO, 1998, p. 17)
}

Dentro de um plano ou de um programa situamos as ações que são classificadas como projeto. O PMBOK, um "Guia de boas práticas", publicado pelo PMI e considerado como a principal ferramenta para a profissão de gerenciamento de projetos, define "projeto" como "um esforço temporário empreendido para criar um produto, serviço ou resultado exclusivo". (PMI, 2017).

É importante destacar, de início, o que se configura como uma das principais características de um projeto, que é a questão do tempo, sendo que a sua natureza temporária indica um início e um término definidos. Sendo assim, um projeto pode ser entendido como "um conjunto de ações, executadas de forma coordenada por uma organização transitória, ao qual são alocados os insumos necessários para, em um dado prazo, alcançar um objetivo determinado”. (VALERIANO, 1998, p.19). Esses objetivos do projeto podem ser de vários tipos, desde a produção de um novo produto ou serviço, 
a construção de um empreendimento, a execução de um trabalho específico em uma comunidade, entre tantos outros possíveis. Considerando as características presentes neste conjunto de ações denominadas como "projeto", o PMI define o gerenciamento de projetos como sendo "a aplicação de conhecimento, habilidades, ferramentas e técnicas às atividades do projeto a fim de atender aos seus requisitos". (PMI, 2017). Assim, gerenciar um projeto inclui:

\begin{abstract}
"Identificação dos requisitos; adaptação às diferentes necessidades, reocupações e expectativas das partes interessadas à medida que o projeto é planejado e realizado; Balanceamento das restrições conflitantes do projeto que incluem, mas não se limitam a: Escopo, Qualidade, Cronograma, Orçamento, Recursos e Risco.” (PMI, 2017, p. 6)
\end{abstract}

O Guia de Gerenciamento de Projetos chama atenção para a importância da relação entre esses fatores mencionados acima, sendo que, no caso de mudança ou alteração em algum deles, pelo menos um outro fator certamente será afetado. Assim, ressalta-se a importância da atuação da equipe de projetos na avaliação das situações a fim de manter o equilíbrio das demandas do projeto e dos stakeholders e as relações entre estes fatores.

Por se tratar de um processo com duração finita, com o objetivo a ser alcançado dentro de um determinado prazo, o projeto tem início e fim, passando por algumas fases que propiciam melhor controle gerencial e são chamadas de ciclo de vida do projeto. Segundo Maximiano (1997), o entendimento do ciclo de vida permite a visualização sistêmica do projeto, desde seu inicio até a conclusão, facilitando o estudo e a aplicação das técnicas de administração de projetos. (MAXIMIANO, 1997, p. 45)

Valeriano (1998) afirma que há diferentes versões para cada ciclo, sendo que algumas contém poucas fases e outras contém mais de uma dezena. No entanto, convencionou-se chamar de ciclo de vida genérico de um projeto a sequência de 4 fases, às quais podem ser reduzidos os demais ciclos: fase conceptual, que inclui desde a ideia inicial do produto ou assunto a ser pesquisado até a elaboração da proposta e a aprovação; fase de planejamento e organização, em que o projeto é planejado e organizado com os detalhes necessários à execução e o controle; fase de implementação, que compreende a execução propriamente dita das tarefas sob a coordenação e liderança do gerente; e a fase de encerramento, em que se efetiva a transferência dos resultados do projeto com a aceitação do seu cliente, seguida de uma avaliação geral do projeto. 
Confirmando as palavras do autor, o PMI (2017) considera que os projetos podem variar em tamanho e complexidade. Contudo, de acordo com o guia, mesmo grandes ou pequenos, simples ou complexos, os projetos podem ser mapeados para seguir a estrutura de ciclo de vida que abarca o início do projeto, a organização e preparação, a execução do trabalho e do projeto e o encerramento do projeto.

Dentro do ciclo de vida, situamos as chamadas áreas gerenciais do projeto. Como foi mencionado anteriormente, os projetos podem variar em tamanho e complexidade, e, sendo assim, como nos esclarece Carvalho e Rabechini Jr. (2011), cada tipo de projeto demanda tratamento diferenciado no que concerne ao seu gerenciamento. Dessa forma, os projetos poderão ter variáveis distintas a serem controladas, o que pode implicar também no aumento de áreas a serem gerenciadas dentro de um projeto.

O PMI (2017) destaca dez áreas do conhecimento: gestão de escopo, gestão do cronograma, gestão de custo, gestão de recursos, gestão da comunicação, gestão de risco, gestão de aquisição, gestão da integração, gestão da qualidade e gestão das partes interessadas. Essas áreas são vistas de forma matricial por cinco grupos de processos, sendo iniciação, planejamento, execução, monitoramento e controle e encerramento (CARVALHO, 2011). Cada uma dessas dez áreas contempla uma infinidade de técnicas e atividades, não sendo o objetivo deste trabalho tratar cada uma delas com profundidade, apenas mencioná-las como elementos fundamentais dentro do gerenciamento de projetos.

Os conceitos que compõe o gerenciamento de projetos e que foram tratados até aqui nos permitem compreender os aspectos fundamentais da área. No próximo tópico trataremos da questão das microempresas, do empreendedorismo e do setor alimentício do município de Betim, para que possamos adentrar nas análises dos dados obtidos na pesquisa de campo realizada neste trabalho.

\subsection{Micro e pequenas empresas: um segmento promissor}

Para melhor compreensão das informações do público alvo da pesquisa, é importante que primeiro se esclareça algumas definições acerca da estrutura institucional destes estabelecimentos. Como mencionado no início deste trabalho, foram abordados restaurantes do município de Betim/MG, que se enquadram na modalidade de micro ou pequenas empresas. 
De acordo com a definição apresentada pelo Serviço Brasileiro de Apoio às Micro e Pequenas Empresas - SEBRAE (2013), são considerados como micro empresas os estabelecimentos do setor de comércio e serviços que apresentam em seu quadro funcional até 9 pessoas ocupadas. Além disso, são avaliados como pequenas empresas os estabelecimentos que apresentam de 10 a 49 pessoas em seus quadros de funcionários. (SEBRAE, 2011)

O SEBRAE também divide os pequenos negócios em quatro segmentos por faixa de faturamento, com exceção do pequeno produtor rural. Tal segmentação segue os critérios da Lei Complementar 123/2006, também chamada de Lei Geral das Micro e Pequenas Empresas. Resumidamente, os pequenos negócios são divididos da seguinte maneira:

1) Empreendedor Individual - Faturamento até $\mathrm{R} \$ 60$ mil;

2) Microempresa - Faturamento até $\mathrm{R} \$ 360$ mil;

3) Empresa de Pequeno Porte - Faturamento entre $\mathrm{R} \$ 360$ mil e $\mathrm{R} \$ 3,6$ milhões;

4) Pequeno Produtor Rural - Propriedade com até 4 módulos fiscais ou faturamento de até $\mathrm{R} \$ 3,6$ milhões.

Os estudos realizados pelo SEBRAE apontam a importância da atuação destas micro e pequenas empresas (MPEs) na economia do país nos últimos anos. O bom desempenho das MPEs na primeira década do século XXI apenas confirmou a sua importância na economia. Em 2010, as micro e pequenas empresas foram responsáveis por $99 \%$ dos estabelecimentos, $51,6 \%$ dos empregos formais privados não agrícolas no país e quase $40 \%$ da massa de salários. Em média, durante a década de 2000, de cada $\mathrm{R} \$ 100$ pagos aos trabalhadores no setor privado não-agrícola, aproximadamente R 41 foram gerados pelas micro e pequenas empresas." (SEBRAE, 2011, p. 13)

Ainda de acordo com os levantamentos do SEBRAE, entre 2000 e 2010, as micro e pequenas empresas criaram 6,1 milhões de empregos com carteira assinada, elevando o total de empregos nessas empresas de 8,6 milhões de postos de trabalho, em 2000, para 14,7 milhões, em 2010. Ademais, o setor do comércio manteve-se como o setor com maior número de MPEs, respondendo por mais da metade do total das MPEs brasileiras. (SEBRAE, 2011).

\footnotetext{
“As micro e pequenas empresas são responsáveis por mais da metade dos empregos com carteira assinada do Brasil. Se somarmos a isso a ocupação que os empreendedores geram para si mesmos, pode-se dizer que os
} 
empreendimentos de micro e pequeno porte são responsáveis por, pelo menos, dois terços do total das ocupações existentes no setor privado da economia.” (SEBRAE, 2011, p. 4)

A partir destas informações, é possível percebermos a importância da existência destas micro e pequenas empresas para a economia do país, sendo necessário que ocorram investimentos tanto nas politicas de crédito e incentivo ao micro e pequeno empresário, quanto nos planos de negócios e na capacitação dos responsáveis pela gerência destes estabelecimentos.

Segundo Melo et al (2012), para melhorar o negócio é de fundamental importância observar as oportunidades de melhoria que auxiliem na sobrevivência no mercado. O espírito criativo e empreendedor tornam possíveis atingir os caminhos e soluções que atendam a exigência dos clientes e do mundo dos negócios. No entanto, os empreendedores podem contar com técnicas e ferramentas existentes no gerenciamento de projetos que auxiliem na busca de soluções eficientes para o negócio.

Para Kerzner (2006), uma boa metodologia de gestão de projetos servirá a todos os interessados diretos do empreendimento, que incluem as pessoas que investiram na empresa e por isso têm direito a exigir um bom desempenho. Nesse cenário, Carvalho e Rabechini Jr. (2011) afirmam que a área de projetos tem assumido maior importância nas empresas, pois estas têm passado por um processo de transformação, organizandose para poder dar respostas eficazes e ágeis às questões ambientais e organizacionais.

Dessa forma, o gerenciamento de projetos tem despontado como uma considerável ferramenta para os empreendedores que atuam nestas micro e pequenas empresas, devido aos seus recursos que podem oferecer grandes auxílios na condução e gestão dos negócios.

\subsection{0 contexto no Município de Betim}

O município de Betim está localizado na região metropolitana de Belo Horizonte/MG, a 35 quilômetros da capital do estado de Minas Gerais. Com uma área de $343 \mathrm{Km} 2$, a cidade tem 432.575 mil habitantes e faz divisa com os municípios de Esmeraldas, Contagem, Juatuba, Igarapé, Ibirité, São Joaquim de Bicas, Mário Campos e Sarzedo. (IBGE, 2018). De acordo com o site da prefeitura do município: 
uma importante rota de bandeirantes que vinham de São Paulo a Pitangui. Assim como várias cidades surgiram nas trilhas das tropas e nas rotas dos bandeirantes, Betim, antes de assim se chamar, fazia parte desse entrecruzar de caminhos, sendo passagem e pousada de tropeiros. Na década de quarenta, instalaram-se as primeiras indústrias de Betim, ligadas à constituição do Parque Siderúrgico Nacional: Cerâmica Saffran (1942), Ikera (1945), Cerâmica Minas Gerais (1947)". (PREFEITURA DE BETIM, 2013).

A partir de então, a cidade começou a ganhar destaque se tornando um grande polo industrial do estado de Minas Gerais:

\begin{abstract}
"Betim, por sua oferta privilegiada de infraestrutura, passou a ser um polo de atração de indústrias. Na década de cinquenta, o planejamento estadual destinou a Betim duas outras funções econômicas: a industrialização de base, representada pelas siderúrgicas, e a produção de alimentos para o abastecimento local. Nesses últimos 30 anos, o parque industrial de Betim cresceu e se diversificou. Além de polo petroquímico e automotivo, a cidade também abriga importantes empresas nos setores de metalurgia, alumínio, mecânica, serviços e logística." (GUIA BETIM, 2010).
\end{abstract}

No entanto, a proximidade com a capital Belo Horizonte e o foco no setor industrial acabaram resultando em pouco investimento e crescimento no setor de comércio e serviços, principalmente no ramo alimentício. Apesar de ser considerada uma cidade relativamente grande, é recente no município a criação de restaurantes de maior porte e que ofereçam uma gastronomia que vá além do básico.

Dessa forma, ainda são majoritários no município os estabelecimentos alimentícios de pequeno porte, que apresentam, em sua maioria, baixo conhecimento administrativo e de gestão de negócios. Assim, tais empreendimentos muitas vezes se apresentam como investimentos de risco, sendo que em alguns casos acabam por fechar as portas.

É justamente o nível de conhecimento das ferramentas de gerenciamento de projetos que queremos captar dos donos e gerentes destes estabelecimentos, a fim de obtermos maiores informações sobre as dificuldades encontradas por estes no gerenciamento dos seus negócios.

\title{
3 Resultados
}

\subsection{Sobre os proprietários}


Os questionários foram aplicados apenas para os empresários que são proprietários dos estabelecimentos participantes. O GRÁFICO 1 apresenta o nível de escolaridade dos entrevistados.

Gráfico 1 - Nível de escolaridade dos proprietários

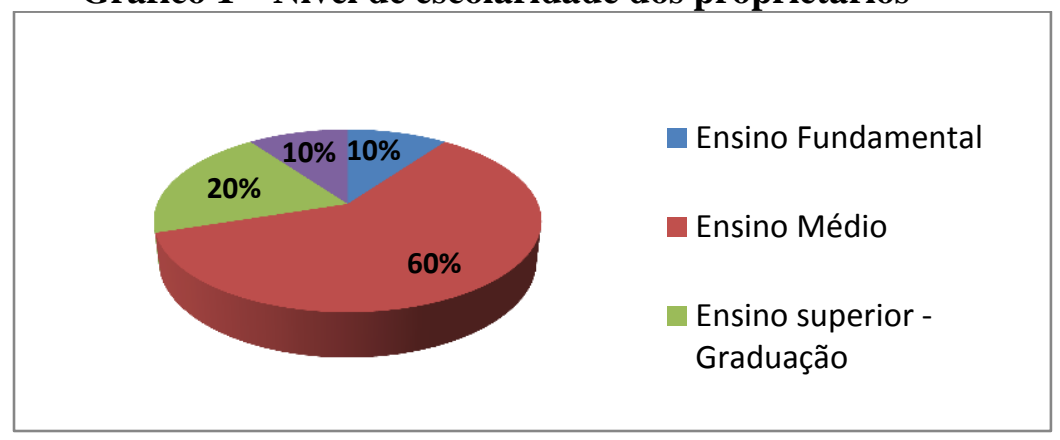

Fonte: dados da pesquisa

\subsection{Sobre o quadro funcional dos estabelecimentos}

De acordo com a definição apresentada anteriormente sobre o número de funcionários contratados em micro e pequenas empresas, os restaurantes pesquisados não excederam um número superior a 49 trabalhadores, como pode ser observado no GRÁFICO 2 a seguir:

Gráfico 2 - Número de funcionários

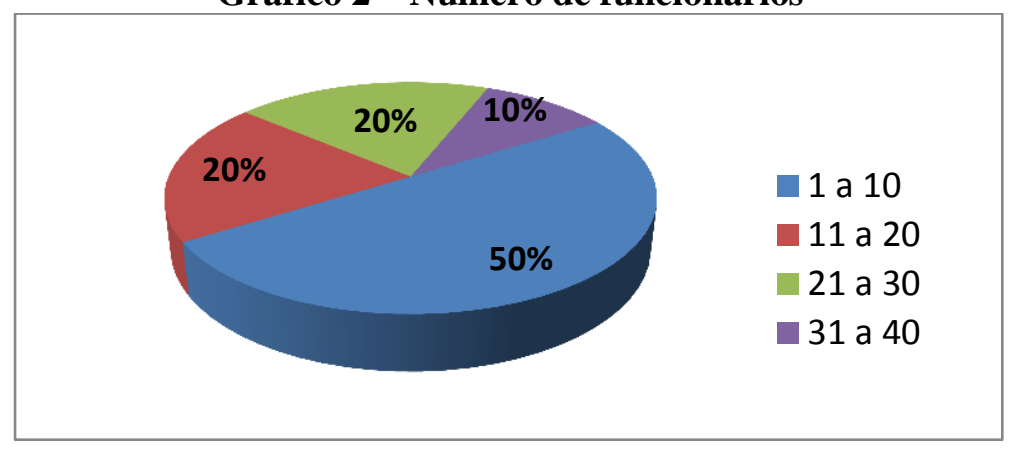

Fonte: dados da pesquisa

\subsection{Sobre o conhecimento das ferramentas de gerenciamento de projetos}

Nesta categoria, foram apresentadas aos proprietários três perguntas, a fim de investigar se estes conheciam Gerenciamento de Projetos, quais processos eles acreditavam que aplicavam em seus estabelecimentos, mesmo não conhecendo tal forma de gestão, e, por fim, qual o nível de interesse em conhecer ou aplicar o Gerenciamento de Projetos em suas empresas. 
Ao serem perguntados se conheciam o Gerenciamento de projetos, $60 \%$ dos entrevistados responderam que não tem nenhum conhecimento acerca de tais ferramentas e, em contraposição, $40 \%$ afirmaram conhecer.

Não obstante, mesmo diante da afirmação do desconhecimento sobre a gestão de projetos, foi apresentada aos entrevistados a pergunta de quais processos de tal prática eles acreditavam utilizar em seus estabelecimentos. O GRÁFICO 3 apresenta os resultados obtidos, sendo que a forma como estão expostos corresponde ao agrupamento de processos utilizados feito por cada proprietário em sua resposta.

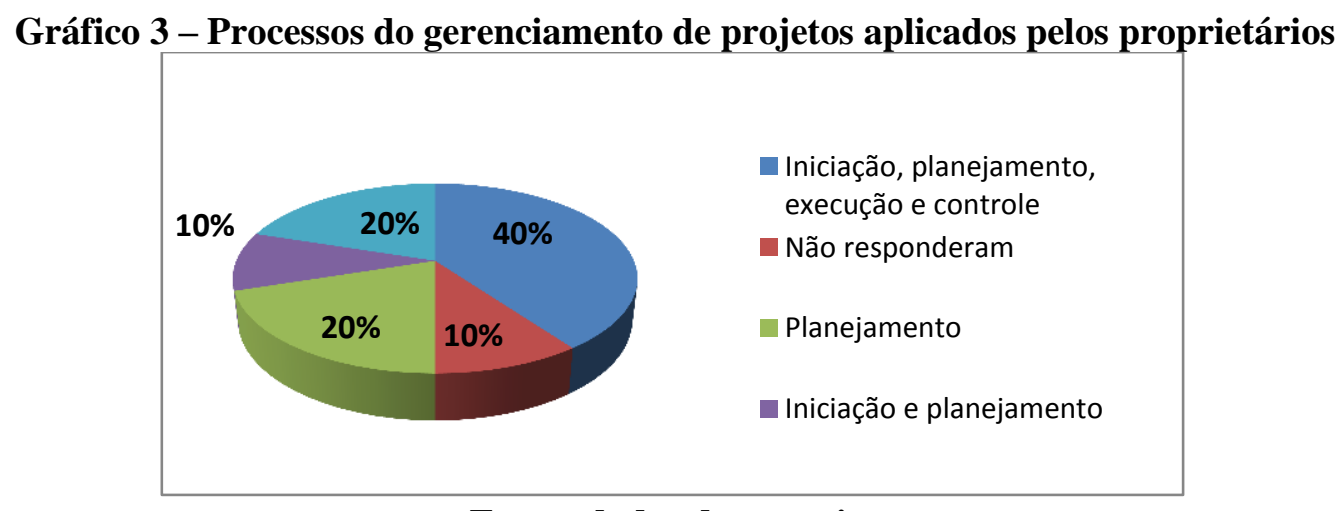

Fonte: dados da pesquisa

\subsection{Sobre a aplicação do gerenciamento de projetos e ferramentas de gestão}

Em quatro perguntas do questionário abordamos os proprietários a respeito da gestão das suas micro e pequenas empresas. Perguntamos aos entrevistados se eles aplicavam o gerenciamento de projetos, se recebiam o auxílio ou consultoria de algum profissional para gerir o empreendimento, se utilizam ferramentas de informática para a gestão e, por fim, quais eram as principais dificuldades encontradas para gerenciar o seu negócio.

Quando perguntados se aplicam o gerenciamento de projetos em seus restaurantes, $80 \%$ dos entrevistados responderam que não, sendo que $20 \%$ afirmaram utilizar as ferramentas. Em seguida, 60\% dos entrevistados afirmaram que não recebem o auxílio de nenhum profissional para a gestão de seus negócios, e 40\% afirmaram que recorrem a este suporte. Dentro desse contingente que recebe auxílio de terceiros, $50 \%$ contam com a prestação de serviços de contabilistas, $25 \%$ de profissionais de comunicação, $25 \%$ de administradores de empresas e $25 \%$ recorrem à consultoria do $\begin{array}{lllll}\text { SEBRAE } & \text { gara } & 0 & \text { negócio. }\end{array}$ No que tange ao uso de ferramentas de informática para a gestão dos 
restaurantes, $70 \%$ dos entrevistados afirmaram utilizar serviços de informática especializados, como a MAFRA (sistema específico para restaurantes), sistemas de “comandas eletrônicas", softwares de gestão de relatórios de contabilidade e também sistemas de gestão e controle de vendas e estoque, gestão de cliente e de gestão de compras. Por conseguinte, $30 \%$ informaram que não utilizam nenhum tipo de ferramenta de informática.

Por fim, perguntamos aos entrevistados quais as maiores dificuldades encontradas na gestão de sua empresa. A contratação de mão de obra qualificada foi quase unanimidade, estando presente em $80 \%$ das respostas. A gestão de pessoas foi o outro ponto mencionado, especificamente o relacionamento dos gestores com os funcionários, contemplando $30 \%$ das respostas presentes nos questionários.

O GRÁFICO 4, a seguir, demonstra o nível de interesse dos empresários entrevistados em conhecer ou aplicar as ferramentas do gerenciamento de projetos em seus estabelecimentos é médio ou grande, chegando a $90 \%$ dos entrevistados:

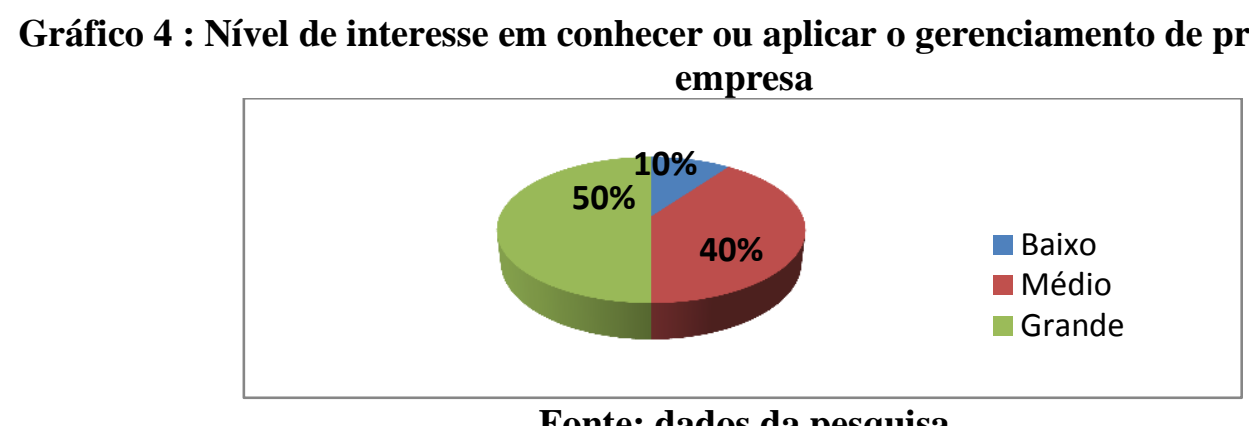

Fonte: dados da pesquisa

\section{Discussão}

Os resultados mostraram que a maioria dos entrevistados possui apenas o Ensino Médio. Apesar disso, $20 \%$ desses disseram ter conhecimento das práticas do Gerenciamento de Projetos. Ao contrário, um dos proprietários que possui o Curso Superior em Administração de Empresas há mais de 20 anos relatou não possuir conhecimentos sobre a Gestão de Projetos. Sendo assim, esse dado comprova o que diz Carvalho (2003) onde o mesmo afirma que a área de Gestão de Projetos ainda tem um grande desenvolvimento pela frente no Brasil, pois existe uma grande lacuna a ser sanada. Tal resultado comprova, também, que a área de Gestão de Projetos no Brasil é recente, uma vez que os Cursos de Administração de Empresas mais antigos não abordavam esta disciplina em sua grade curricular, o que corrobora com a colocação do autor. 
Conforme citado anteriormente, o foco da cidade de Betim é, em sua maioria, industrial. Nesse sentido, os dados acima comprovam que, apesar de um evidente crescimento nesse setor, ainda prevalecem as micro e pequenas empresas, não sendo detectado nesta pesquisa nenhum empreendimento de médio ou grande porte.

Tais resultados corroboram com a hipótese levantada no início deste trabalho, onde presumimos que as práticas semelhantes às do Gerenciamento de Projetos nessas empresas provavelmente eram utilizadas de forma amadora e intuitiva. Tal fato pode ser justificado conforme relatado por Carvalho (2003), pois, antes, quem adotava administração por projetos eram as grandes empreiteiras, órgãos governamentais responsáveis por grandes empreendimentos que variavam de três a cinco anos. Atualmente, houve um notável crescimento da participação de outras empresas. Nesse sentido, um novo perfil de gerente de projetos vem se formando, utilizando assim as técnicas de forma mais profissional visando contribuir para que as empresas busquem melhores resultados.

Diante destes resultados, ficou claro que apesar dos proprietários terem apresentado algum conhecimento sobre gerenciamento de projetos, ainda não é uma prática a contratação de ferramentais e de profissionais especialistas em Gerenciamento de Projetos nesse ramo de negócio. No entanto, como pode ser comprovado no GRÁFICO 4 anteriormente, o nível de interesse dos empresários entrevistados em conhecer ou aplicar as ferramentas do gerenciamento de projetos em seus estabelecimentos é médio ou grande, chegando a $90 \%$ dos entrevistados.

\section{Considerações finais}

Estes resultados sugerem que apesar de não existir, na rotina dos empreendedores estudados, um alto nível de conhecimento das práticas do Gerenciamento de Projetos no ramo de restaurantes na cidade de Betim/MG, tais procedimentos são realizados de forma incipiente, de maneira amadora e intuitiva. Além disso, os números demonstraram que o nível de conhecimento e de aplicação das práticas do gerenciamento de projetos está diretamente relacionado com o nível de escolaridade dos entrevistados, ou seja, aqueles que relataram nível médio e superior demonstraram possuir maior conhecimento e maior interesse na aplicação destas técnicas, o que nos permite inferir sobre uma possível oportunidade de prestação de 
serviços de consultoria nesta área. Além disso, as organizações que adotarem uma filosofia e uma prática madura de gerência de projetos estarão mais aptas ao sucesso em um mercado competitivo do que aquelas que mantêm as mesmas práticas (KERZNER, 2017).

Diante do exposto, propomos, a partir deste estudo, a realização de novas pesquisas visando determinar as melhores práticas do Gerenciamento de Projetos a serem aplicadas nesse ramo de atividade, contribuindo assim para a melhoria da gestão destes estabelecimentos utilizando essa poderosa ferramenta de gestão e consequente melhoria dos resultados.

\section{Referências}

CARVALHO, Marly Monteiro de; RABECHINI JÚNIOR, Roque. Fundamentos em gestão de projetos: construindo competências para gerenciar projetos. 3 . ed. rev. e ampl. São Paulo: Atlas, 2011. xv, 422 p.

CARVAlHO, Marly Monteiro. Fundamentos em Gestão de Projetos. São Paulo: Atlas, 2011.

KERZNER, Harold. Gestão de projetos as melhores práticas. $2^{a}$ edição. São Paulo: Bokkman, 2006.

KERZNER, Harold. Gestão de projetos: melhores práticas. 3. ed. Porto Alegre: Bookman, 2017.

MAXIMIANO, Antonio César Amaru. Administração de projetos: como transformar ideias em resultados. São Paulo: Atlas, 1997. 196p.

MELO, Daniel Reis Armond de. Et al. As Práticas de Gerenciamento de Projetos em Micro e Pequenas Empresas. III Congresso Nacional de Administração e Ciências Contábeis. Rio de Janeiro: 2012.

OLIVEIRA, Sérgio Luiz de. Tratado de Metodologia Científica. 2 ed. São Paulo : Pioneira, 2001.

PARRA FILHO, Domingos. Metodologia Científica. 6 ed. São Paulo: Futura, 1998.

SEBRAE. Anuário do trabalho na micro e pequena empresa: 2010-2011. 4. ed. I Serviço Brasileiro de Apoio às Micro e Pequenas Empresas (Org.); Departamento Intersindical de Estatística e Estudos Socioeconômicos [responsável pela elaboração da pesquisa, dos textos, tabelas e gráficos]. - Brasília, DF; DIEESE, 2011. 204 p. Disponível em: http://www.biblioteca.sebrae.com.br/bds/bds.nsf/25BA39988A7410D78325795D003E8 172/\$File/NT00047276.pdf Acesso em: 28 Maio de 2018. 
SEBRAE. Taxa de sobrevivência das empresas no Brasil. Coleção estudos e pesquisas. Brasília. 2011. Disponível em: http://www.biblioteca.sebrae.com.br/bds/bds.nsf/45465B1C66A6772D8325793000518 16C/\$File/NT00046582.pdf Acesso em: 27 de Maio de 2018.

Serviço Brasileiro de Apoio à Micro e Pequena Empresa Bahia. Estudo sobre a Industria de Panificação, acesso em 19 de abril, 2018. SEBRAE, 2019.

UM GUIA DO CONHECIMENTO EM GERENCIAMENTO DE PROJETOS: GUIA PMBOK. 6. ed. Pennsylvania: Project Management Institute, 2017.

VALERIANO, Dalton L. Gerência em projetos: pesquisa, desenvolvimento e engenharia. São Paulo: Makron Books, 1998. xxvii, 438 p.

VARGAS, Ricardo Viana. Gerenciamento de projetos: estabelecendo diferenciais competitivos. 8. ed. Rio de Janeiro: Brasport, 2016. 